\title{
Overlap joining of aluminium and copper using laser micro welding with spatial power modulation
}

\author{
S. Hollatz ${ }^{1}$ (1) $\cdot$ P. Heinen ${ }^{1} \cdot$ E. Limpert ${ }^{2} \cdot$ A. Olowinsky ${ }^{1} \cdot$ A. Gillner ${ }^{1,2}$ \\ Received: 7 October 2019 / Accepted: 1 January 2020 / Published online: 28 January 2020 \\ (C) The Author(s) 2020
}

\begin{abstract}
The rising demand for high power battery systems for the electric mobility requires the connection of a large number of cells. Due to the functionality of the cell chemistry, a combination of copper and aluminium is necessary. The differing material properties like thermal conductivity as well as the formation of intermetallic phases are challenging for welding processes. This study contains the results for overlap joints of copper and aluminium using a laser beam welding process with spatial power modulation. With a parameter variation, the cross-sectional shape of the weld seams and therefore, the ratio of depth to width can be adjusted. With additional longitudinal cross sections and an energy-dispersive X-ray spectroscopy analysis, the different mixing behaviour of the dissimilar material depending on the top layer is investigated.
\end{abstract}

Keywords Copper $\cdot$ Aluminium $\cdot$ Micro joining $\cdot$ Laser welding $\cdot$ Spatial power modulation $\cdot$ Battery

\section{Introduction}

The worldwide increased attractiveness of electric vehicles leads to rising sales in the last decade [1]. Most of these cars are using lithium-ion batteries as an energy storage system. The battery cells consist of electrodes with a different electrical load. In most cases, the negative anode is made of thin copper foil, while the positive cathode consists of aluminium. The electrodes are coated with active materials and separated by an ion permeable membrane. The stacked or rolled electrodes are placed into a housing and filled with electrolyte [2].

To meet the performance requirements for electric vehicles, multiple cells are connected to a battery module or system. Therefore, a low-resistance connection is necessary to keep the thermal energy loss at the contacts as low as possible. Welding processes like ultrasonic or laser welding are suitable

Recommended for publication by Commission VII - Microjoining and Nanojoining

S. Hollatz

soeren.hollatz@ilt.fraunhofer.de

1 Fraunhofer Institute for Laser Technology ILT, Steinbachstr. 15, 52074 Aachen, Germany

2 RWTH Aachen University, Templergraben 55, 52062 Aachen, Germany to create such contact qualities [3]. Due to the internal design of a battery cell, a combination of copper and aluminium is mandatory. Different material properties and the formation of intermetallic phases in the mixing zone of these materials are challenging for most welding processes.

Today's battery industry has different ways to deal with this issue:

1. A dissimilar joint can be performed inside the cell by welding the copper electrode foils to aluminium, e.g. with ultrasonic welding. That leads to a cell with two aluminium connectors on its outside. This is often used with prismatic battery cells.

2. The copper electrode can be welded to the steel case of a cylindrical cell, while the aluminium electrode is clamped to a steel terminal. The resulting battery cells consist of two steel terminals on its outside.

3. The dissimilar joint is performed outside the cell. Pouch cells for example mostly have a copper and an aluminium terminal on its outside.

The third option leads to the necessity of a joining process for aluminium and copper that is capable to meet the requirements of the growing electric vehicle market. Within this work, a laser welding process for overlap joints of aluminium and copper is investigated. Therefore, a high brilliant laser beam source with additional spatial power modulation is used. 
The aim of the study is to determine the influence of the parameters laser power, feed rate and spatial power modulation on the weld seam geometry and mixing behaviour of the dissimilar materials.

\section{State of the art}

\subsection{Laser beam welding with spatial power modulation}

The laser welding process is based on two process regimes: heat conduction welding and deep penetration welding, see Fig. 1. For heat conduction welding, the materials surface is melted by absorbing the laser beam on the materials' surface. The absorbed energy is transferred inside the material by heat conduction. The resulting weld seams have a small ratio of penetration depth to weld width. When reaching an intensity threshold, the material is vaporized. The resulting recoil pressure causes the formation of a vapour capillary (keyhole) in the material. Inside the keyhole, the laser beam interacts multiple times with the material due to internal reflection which increases the degree of energy coupling. The resulting weld seams are narrow and deep compared with weld seams performed in the heat conduction state [4-6].

To increase the degree of freedom for the manipulation of the weld seam cross section, spatial power modulation is used in combination with the deep penetration welding. Spatial power modulation describes the superposition of the linear feed rate with an oscillation movement, in this case, a circular motion. By using this modulation, the weld seam width is increased and nearly rectangular cross sections can be reached. In overlap joints, the increase of the width is equivalent to a reduction of the electrical transition resistance. The increased width is accompanied by a slight reduction of the weld depth, as the actual path speed is increased due to the oscillation movement. Although linear feed rate and laser power are the same, the overall cross-sectional area is increased [7].

An increase of the process stability and a better controllability of the melt pool dynamics can be observed [7, 8]. Furthermore, the efficiency of the welding process could be increased using a spatial power modulation [9]. The oscillation movement is defined by a different degree of overlapping depending on oscillation parameters and feed rate.

\subsection{Welding of dissimilar materials}

When developing a welding process for dissimilar materials, the different material properties are challenging. In the case of aluminium and copper, there are physical and metallurgical differences that influence the welding process. The melting temperature of copper is about $400 \mathrm{~K}$ higher than the melting point of aluminium. That leads to additional temperatureinduced dynamics in the melt pool due to the higher temperature gradient. During cooling, the different solidification can cause tensions in the weld seam that may lead to cracks [10]. This effect is amplified by the different coefficient of thermal expansion, see Table 2 .

From a metallurgical point of view, the materials are not completely soluble in each other in the solid state. During cooling, intermetallic phases are formed in the weld seam. These phases have a significant higher hardness and a higher electrical resistance. The resulting joints can be brittle and tend to crack. In Table 1, the properties of the possible intermetallic phases are shown [11].

Possible welding processes are, e.g. electron beam welding, ultrasonic welding, resistance or laser beam welding. For ultrasonic welding, the overlapping materials are welded under pressure due to ultrasonic vibrations in the tool. The process can produce dissimilar joints with low heat input and low mixing of the materials. Disadvantageous are vibration stress on the component, the sensitivity of the process to the surface condition and its limitation regarding material thickness [3, 13]. In resistance welding, a high electrical current flows through the joining partners, heats the material up and creates a spot weld. This easy and cheap process is commonly used in the industry. Regarding copper and aluminium, the high thermal and electrical conductivity is a challenge for the process and increases the electrode wear [3]. Electron and laser beam welding are both contactless processes. In difference to electron beam welding, laser beam welding is not dependent on an expensive and elaborate vacuum. Further
Fig. 1 Process stages of laser welding processes [5]

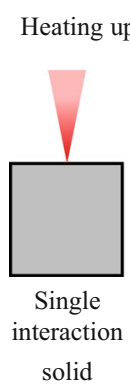

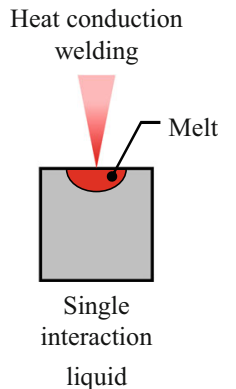
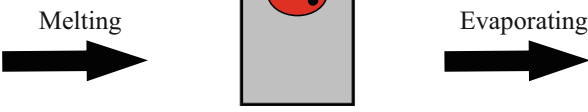

liquid

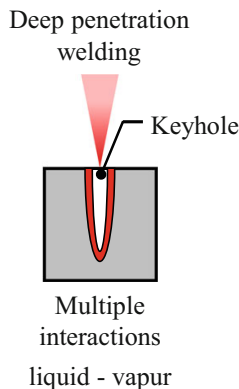


Table 1 Properties of aluminium and copper intermetallic phases [12]

\begin{tabular}{llllll}
\hline Phase & Composition & $\begin{array}{l}\mathrm{Cu} \\
\text { Mass }(\%)\end{array}$ & $\begin{array}{l}\mathrm{Al} \\
\text { Mass }(\%)\end{array}$ & $\begin{array}{l}\text { Hardness } \\
\mathrm{HV}\end{array}$ & $\begin{array}{l}\text { Spec. el. resistance } \\
\mu \Omega \times \mathrm{cm}\end{array}$ \\
\hline $\mathrm{Cu}$ & $\mathrm{Cu}$ & 100 & 0 & 100 & 1.75 \\
$\gamma 1$ & $\mathrm{Cu}_{9} \mathrm{Al}_{4}$ & 80 & 20 & 1050 & 14.2 \\
$\delta$ & $\mathrm{Cu}_{3} \mathrm{Al}_{2}$ & 78 & 22 & 180 & 13.4 \\
$\zeta 2$ & $\mathrm{Cu}_{4} \mathrm{Al}_{3}$ & 75 & 25 & 624 & 12.2 \\
$\eta 2$ & $\mathrm{CuAl}^{2}$ & 70 & 30 & 648 & 11.2 \\
$\theta$ & $\mathrm{CuAl} 2$ & 55 & 45 & 413 & 8 \\
$\mathrm{Al}$ & $\mathrm{Al}$ & 0 & 100 & 60 & 2.9 \\
\hline
\end{tabular}

advantages of laser beam welding are short process times and good automation possibilities.

For laser beam welding, common fibre lasers with infrared wavelength $(1070 \mathrm{~nm})$ can be used. High focusability leads to high intensity for enabling a stable keyhole welding process [7]. This process step is recommended to achieve an efficient weld seam because of the increased energy incoupling inside the keyhole. Talking about copper materials, the absorptivity of the infrared wavelength is less than $10 \%$ in solid state at room temperature. Using wavelengths in the visible range, for example green $(515 \mathrm{~nm})$, the absorptivity increases to $35 \%$ or more, which leads to a higher energy incoupling in the deep penetration state and reduced dependence on the surface oxidization of copper materials [5].

However, the available green and blue $(450 \mathrm{~nm})$ laser beam sources still have limited beam quality and power as well as high investment costs. For this investigation, a state-of-the-art single-mode fibre laser is used. With similar laser systems, $[10,14]$ have already done investigations on laser beam welding with a superimposed oscillation movement. While [10] has performed weld seams with a linear oscillation perpendicular to the feed rate, crack-free weld seams in copper and aluminium could be achieved. [14] is focusing on the resulting electrical contact resistance that can reach nearly the theoretical minimum. The increased joining width due to the used oscillation movement is beneficial for the contact resistance.

\section{Experimental setup}

The investigations are performed with a single-mode fibre laser (IPG Laser YLS1000SM) with a maximum power of $1000 \mathrm{~W}$ and a wavelength of $1070 \mathrm{~nm}$. A f-theta optics (Sill Optics) with a focal length of $163 \mathrm{~mm}$ creates a Gaussian beam profile with a focal diameter of $24 \mu \mathrm{m}$ and a Rayleigh length of $0.24 \mathrm{~mm}$. Using a galvanometric scanner, the laser beam can be moved on a two-dimensional plane. The intelliscan 25 (Scanlab $\mathrm{GmbH}$ ) is also able to apply the spatial power modulation.
For the investigation, aluminium $\mathrm{Al} 99.5$ and copper $\mathrm{Cu}$ ETP are used, due to their wide distribution, availability and purity. The material properties are shown in Table 2. The metal sheets have a size of $40 \mathrm{~mm}$ in length, $20 \mathrm{~mm}$ in width, and $0.5 \mathrm{~mm}$ thickness.

The copper and aluminium sheets are placed in a clamping device that guarantees a reproducible and gapless positioning in overlap configuration. The welding zone is flooded with argon as shielding gas $(\sim 30 \mathrm{l} / \mathrm{min})$. The probes are cleaned with ethanol before welding. For all investigations, the weld seams have a length of $10 \mathrm{~mm}$. Experiments are conducted with aluminium on top of the copper sheet and also vice versa.

The investigation is divided into three steps:

1. Initial situation without spatial power modulation

2. Investigation of the influence of the spatial power modulation on the cross-sectional shape

3. Investigation of reproducibility, intermetallic mixing and tensile strength

In the first step, the initial situation with a conventional welding process is investigated. Therefore, the influence of laser power and feed rate is investigated based on metallographic analysis. The experiments are performed with one specimen per parameter set to investigate a large range of parameters. The probes are compared concerning their connection width and penetration depth. All cross sections are made at a similar position in the middle of the weld seam.

Table 2 Material properties of Al 99.5 and Cu-ETP [15-17]

\begin{tabular}{llll}
\hline Material property $(T=20 \mathrm{C})$ & Unit & $\mathrm{Al} 99.5$ & $\begin{array}{l}\mathrm{Cu}- \\
\text { ETP }\end{array}$ \\
\hline Density & $\left(\mathrm{g} / \mathrm{cm}^{3}\right)$ & 2.7 & 8.9 \\
Absorption $(\lambda \approx 1 \mu \mathrm{m})$ & $(\%)$ & $\approx 7$ & $\approx 3$ \\
Melting point & $\left({ }^{\circ} \mathrm{C}\right)$ & 660 & 1083 \\
Electrical conductivity & $(\mathrm{MS} / \mathrm{m})$ & $34-36$ & 57 \\
Thermal conductivity & $\left(\mathrm{W} / \mathrm{m}^{-1} \mathrm{~K}^{-1}\right)$ & $210-220$ & 394 \\
Coefficient of thermal expansion & $\left(10^{-6} \cdot \mathrm{K}^{-1}\right)$ & 24 & 17 \\
\hline
\end{tabular}


Fig. 2 Results with conventional laser welding of arrangement 1 (left) and 2 (right)
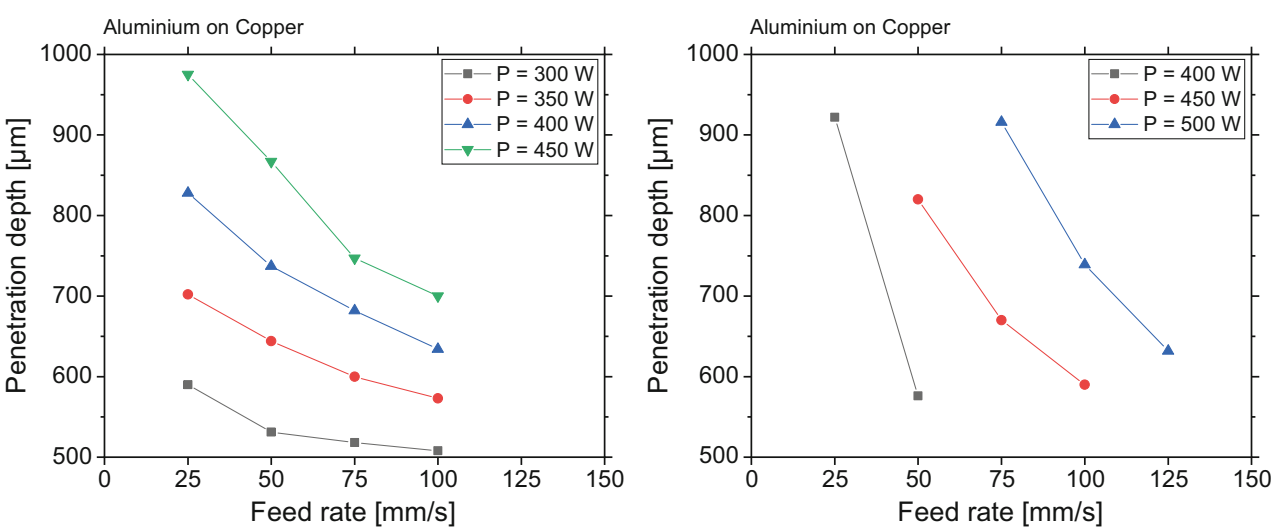

In the second stage, spatial power modulation is used to influence the weld seam shape. Based on a starting parameter set, the feed rate, laser power, oscillation amplitude and oscillation frequency are varied one by one.

With a chosen parameter set from the second step, investigations concerning the reproducibility, mechanical strength and occurrence of intermetallic phases are performed. The width and depth of the weld seam are investigated with five probes per parameter set. To determine the mechanical strength, another five specimens are tested with a Zwick SMZ 100. The intermetallic phases and the mixing of the material are shown by longitudinal cross sections and an energy dispersive X-ray spectroscopy.

\section{Results and discussion}

\subsection{Conventional laser welding}

The results of the welding tests without spatial power modulation are shown in Fig. 2. The welding depth is plotted above the feed rate. Different curves represent different laser powers. On the left side, the results are obtained with aluminium as top layer (arrangement 1), while on the right side, copper is on top (arrangement 2 ). It is visible that the penetration depth decreases with increasing feed rate for both arrangements. In order to obtain a comparable welding depth at the same feed rate, more laser power is required for arrangement 2 with copper on top. Furthermore, the influence of a change in speed is stronger in arrangement 2, visible by steeper lines in Fig. 2.

For the following investigations with spatial power modulation, a feed rate of $50 \mathrm{~mm} / \mathrm{s}$ is used. The laser power for arrangement 1 will be $400 \mathrm{~W}$ and for copper as top layer, it will be $450 \mathrm{~W}$. Reference cross sections of these parameters without oscillation are shown in Fig. 3.

The cross sections show a wide melt pool in aluminium and a narrow weld seam in the copper. These geometries are typical for overlap joints of aluminium and copper [10]. The reasons for that behaviour lie in the different melting point and heat conductivity.

\subsection{Influence of spatial power modulation}

Using spatial power modulation, differences in the crosssectional weld seam shape are visible. The influence of each parameter is compared on the basis of the connection width and penetration depth. Differences in colour indicating the mixing of the materials are also recognizable in the cross sections.
Fig. 3 Cross section of arrangement 1 (left) and 2 (right)
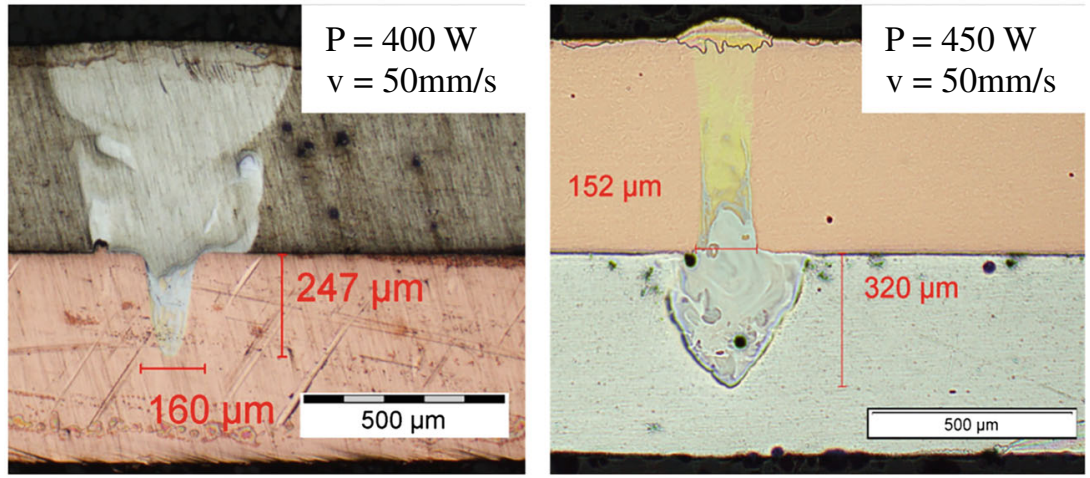


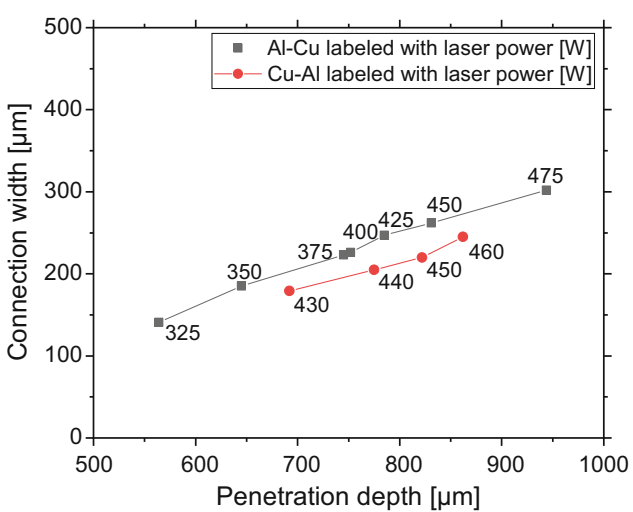

Fig. 4 Results of laser power variation ( $v=50 \mathrm{~mm} / \mathrm{s}, a=0.1 \mathrm{~mm}, f=$ $1000 \mathrm{~Hz})$

\subsubsection{Laser power}

With constant parameters, the laser power is varied for both arrangements. The results of depth and width in the cross sections are shown in Fig. 4. Each measurement point is marked with the used laser power. Outside of this parameter range, there was no connection or a full penetration of the lower joining partner.

With rising power, especially, the depth of the weld seam is increasing, while the connection width can be changed by varying the amplitude. For aluminium as a top layer, a wider area with valid measurements is visible. The range is about $150 \mathrm{~W}$ for achieving weld seams without full penetration. Using arrangement 2 , a difference of about $30 \mathrm{~W}$, investigated with a power increment of $10 \mathrm{~W}$, changes the process from no connection to full penetration. This behaviour can be explained with the difference in melting points. When the copper material is penetrated, the temperature of the copper is higher than $1083{ }^{\circ} \mathrm{C}$. The aluminium with its lower melting point is directly liquid in the transition area, and the laser beam guided through the keyhole is partially absorbed in the aluminium and leads to an even higher energy input in the aluminium. With aluminium as a top layer, the copper behaves like a heat sink.

Cross sections are shown in Fig. 5. In this case, arrangement 1 with an amplitude of $0.1 \mathrm{~mm}$ with $350 \mathrm{~W}$ and $475 \mathrm{~W}$ is chosen to show the differences in penetration depth. Besides, the colour of the molten material is different. On the left side, a clear border between copper and aluminium is visible, while dark grey and golden areas occur in the transition area on the right side. These areas indicate a mixing of the materials and most likely an occurrence of intermetallic phases. In comparison with Fig. 3, especially, the weld seam shape in copper (arrangement 1) has changed from a narrow tip to a wider area.

\subsubsection{Feed rate}

Analogous to the investigations with the changed power, tests are carried out with the feed rate. For arrangement 1 , the feed rate could be changed from 10 to $120 \mathrm{~mm} / \mathrm{s}$ with $P=400 \mathrm{~W}$, $a=0.1 \mathrm{~mm}$ and $f=1000 \mathrm{~Hz}$. The width at the connection is between 150 and $250 \mu \mathrm{m}$. With increasing feed rate, the measured connection width and also the weld depth decreased. The same behaviour is seen with arrangement 2, but, comparable with the variation of the laser power, the range of usable parameters is reduced. With $450 \mathrm{~W}$ and the same oscillation parameters, weld seams without full penetration could be achieved with feed rates from 50 to $90 \mathrm{~mm} / \mathrm{s}$.

With higher feed rates $(>120 \mathrm{~mm} / \mathrm{s})$, the laser power is not high enough to result in a continuous weld seam. Instead, the difference in path speed due to the oscillation is visible. Using a circular oscillation, there is a fast and a slow side. On the fast side, the feed rate and the speed of the oscillation movement aim in the same direction. On the other side of the circle, the feed rate and oscillation speed aim in different directions and reduce the total path speed at this position. This results in partially welded seams because the energy input on the slow side is higher due to the longer time of exposure.

\subsubsection{Oscillation amplitude}

With variation of the oscillation amplitude, a transformation of the weld seam shape to a nearly rectangular weld seam shape can be performed. Therefore, cross sections of three examples for arrangement 1 are shown in Fig. 6.
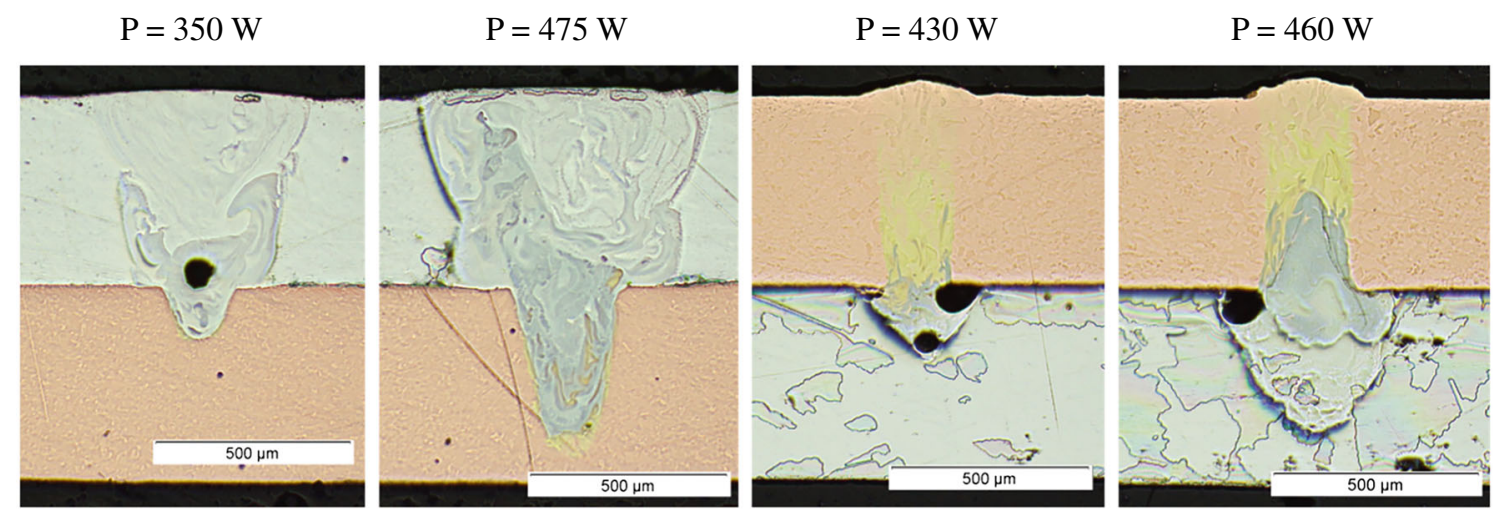

Fig. 5 Cross sections with different laser power for both arrangements $(v=50 \mathrm{~mm} / \mathrm{s}, a=0.1 \mathrm{~mm}, f=1000 \mathrm{~Hz})$ 
Fig. 6 Cross sections with $P=$ $450 \mathrm{~W}, v=50 \mathrm{~mm} / \mathrm{s}, f=1000 \mathrm{~Hz}$ and different amplitudes in arrangement 1
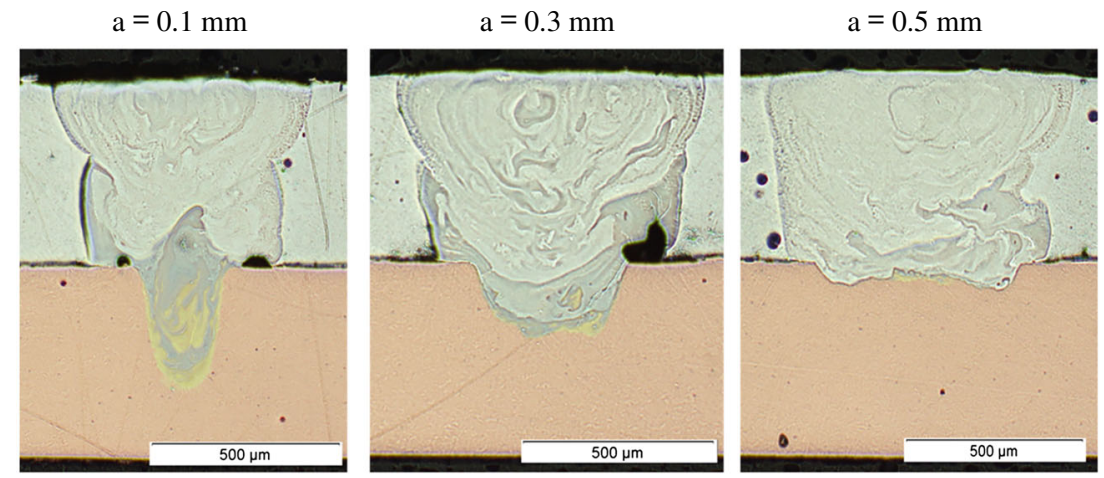

The amplitude indicates the radius of the circular oscillation movement. Increasing the amplitude leads to an increase of the weld width and a decrease of the penetration depth. The amplitude by itself is limited due to the scanner performance. An increased amplitude leads to a higher path speed. Changing the amplitude from 0.1 to $0.5 \mathrm{~mm}$ with fixed frequency, the path speed changes from about 600 to $3000 \mathrm{~mm} / \mathrm{s}$. With path speeds this high, the used scanner system reaches its limits due to the rotational inertia of the moving mirror. Figure 6 shows that the connection width is not increased in the same way the amplitude is increased. Rather, it can be seen that a minimum width cannot be undercut (see Fig. 3 without oscillation), and the difference of a factor of five between the amplitude of the left and right cross section in Fig. 6 does not lead to a comparable change in width.

For arrangement 2, changing the amplitude is more challenging due to the narrow process window. By increasing the amplitude, the laser power needs to be adjusted also to achieve a connection between the two welding partners. In Fig. 7, three cross sections are shown. The width in the copper layer is changing due to the changed amplitude. Also visible is a colourful mixing of the materials all along the weld seam depth.

\subsubsection{Oscillation frequency}

By changing the frequency of the oscillation movement, the path speed and the degree of overlap are changed. As a result, the weld seam geometries are changing, see Fig. 8. With low frequencies, a wider weld seam is achieved, while higher frequencies create wider weld seams. In the case with low frequencies, the time between two circles is larger, and the heat has more time to dissipate. With a higher frequency, the heat is concentrated in the middle of the weld seam and leads to deeper weld seams. Additionally, the lack of scanner performance at high frequencies can lead to an incomplete amplitude and thus to a narrower weld seam. The increased weld seam depth results again in an increased mixing of the two materials, due to the larger percentage of the lower material in the melt pool.

\subsection{Reproducibility tests}

For further testing, parameter sets with $v=50 \mathrm{~mm} / \mathrm{s}, a=$ $0.1 \mathrm{~mm}$ and $P=400 \mathrm{~W}$ for arrangement 1 and $450 \mathrm{~W}$ for arrangement 2 are chosen. With these oscillation parameters, a degree of overlapping of over $70 \%$ is reached. The penetration depth of both parameter sets is nearly half the thickness of
Fig. 7 Cross sections with $v=$ $50 \mathrm{~mm} / \mathrm{s}, f=1000 \mathrm{~Hz}$ and different amplitudes and adjusted laser power in arrangement 2
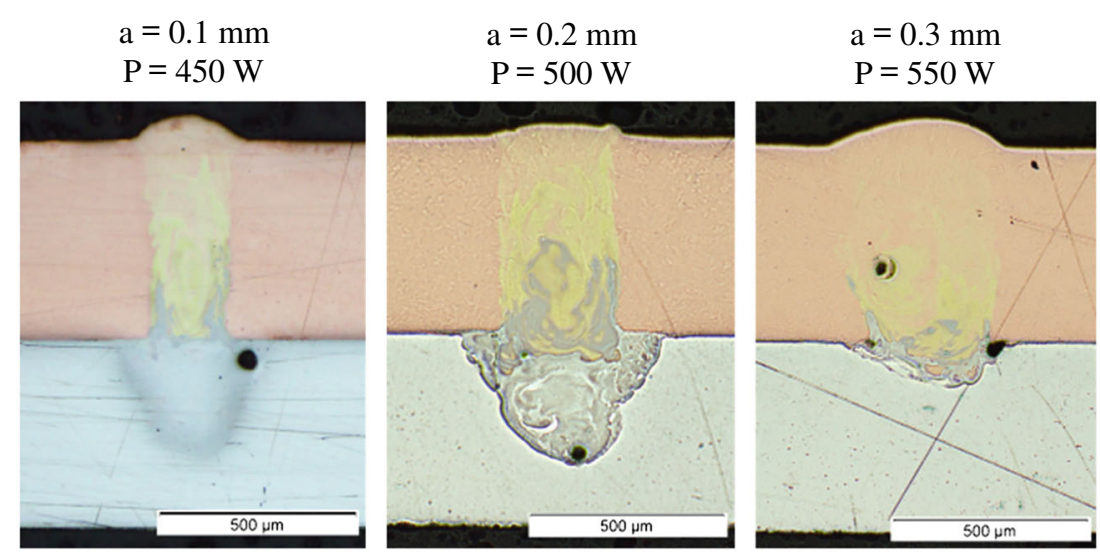

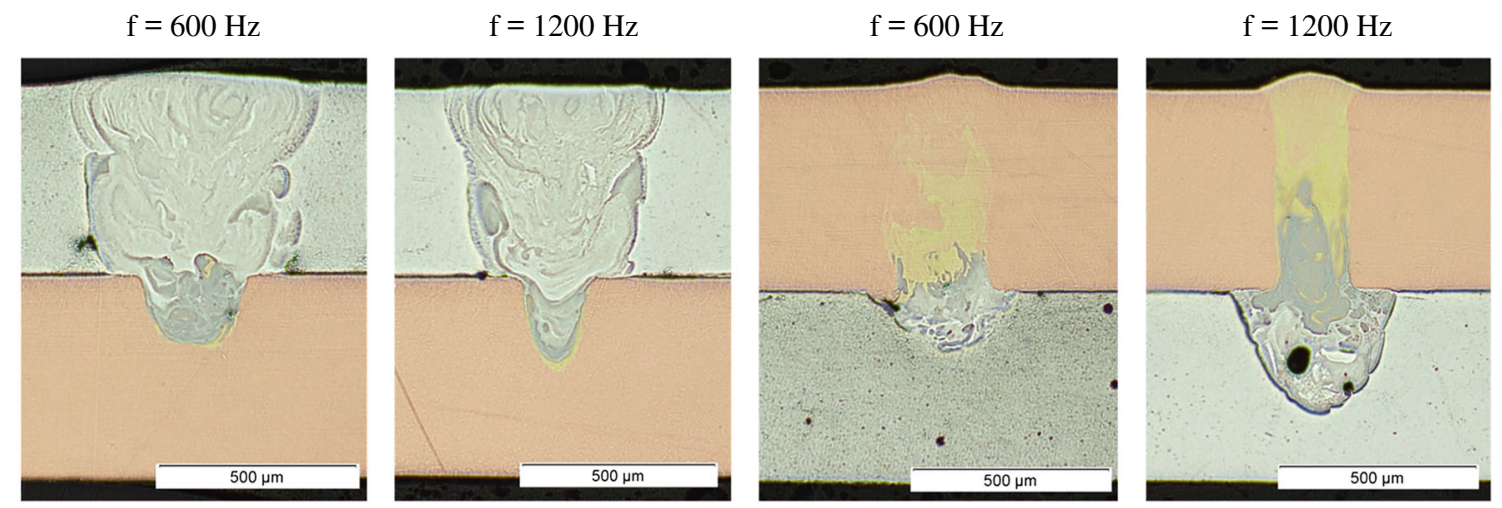

Fig. 8 Cross sections with $v=50 \mathrm{~mm} / \mathrm{s}, a=0.1 \mathrm{~mm}$ and different frequencies and adjusted laser power in arrangement $1(2$ left, $P=400 \mathrm{~W})$ and $2(2$ right, $P=450 \mathrm{~W}$ )

the bottom layer, which ensures a connection. These parameters are in the centre of the usable range of parameters and are therefore suitable for the reproducibility tests.

Analysing cross sections of five specimens welded in arrangement 1 leads to a mean weld depth of $732 \mu \mathrm{m}$ with $7-\mu \mathrm{m}$ standard deviation, see Fig. 9. With the same standard deviation, the weld seam width in the transition is measured to $227 \mu \mathrm{m}$. For the whole depth (including the thickness of the top layer), the deviation is relatively low, which leads to the conclusion that the process is reproducible.

For arrangement 2 , the connection width with a mean value of $217 \mu \mathrm{m}$ and a standard deviation of $8 \mu \mathrm{m}$ is measured. This value is in the same range as for arrangement 1 , but comparing the weld depth in the bottom layer arrangement 2 shows a larger variation. Measured depths from 250 to $333 \mu \mathrm{m}$ lead to a mean value of $293 \mu \mathrm{m}$ with a standard deviation of $36 \mu \mathrm{m}$.

Using the cross sections, the melt pool area is measured and shown in the right diagram of Fig. 9. In arrangement 1, $80 \%$ of the molten material is aluminium, while in arrangement 2 , the ratio is more balanced with $40 \%$ aluminium. The balancing might have an influence on the occurrence of intermetallic phases.

\subsubsection{Intermetallic phases}

The intermetallic mixing has an influence on the mechanical and electrical properties of the weld seam. To investigate the mixing and the melt flow of the material, an energy-dispersive $\mathrm{X}$-ray (EDX) spectroscopy of the transverse cross sections and additional longitudinal cross sections is performed. The pictures of the cross sections taken by a scanning electron microscope for the two arrangements are shown in Fig. 10. The EDX shows an occurrence of 22 -compound (see Table 1) in the centre of the cross section of arrangement 1 (Fig. 10, left). This phase is positioned under the connection level of the joint material. In comparison, the intermetallic phases of arrangement 2 are positioned directly in the transition between the two materials. The investigation shows a mixing that might relate to the $\gamma_{1}$-phase with $80 \mathrm{wt} \%$ of copper. Close to this spot, a compound comparable with the $\theta$-phase with about $55 \mathrm{wt} \%$ of copper is measured.
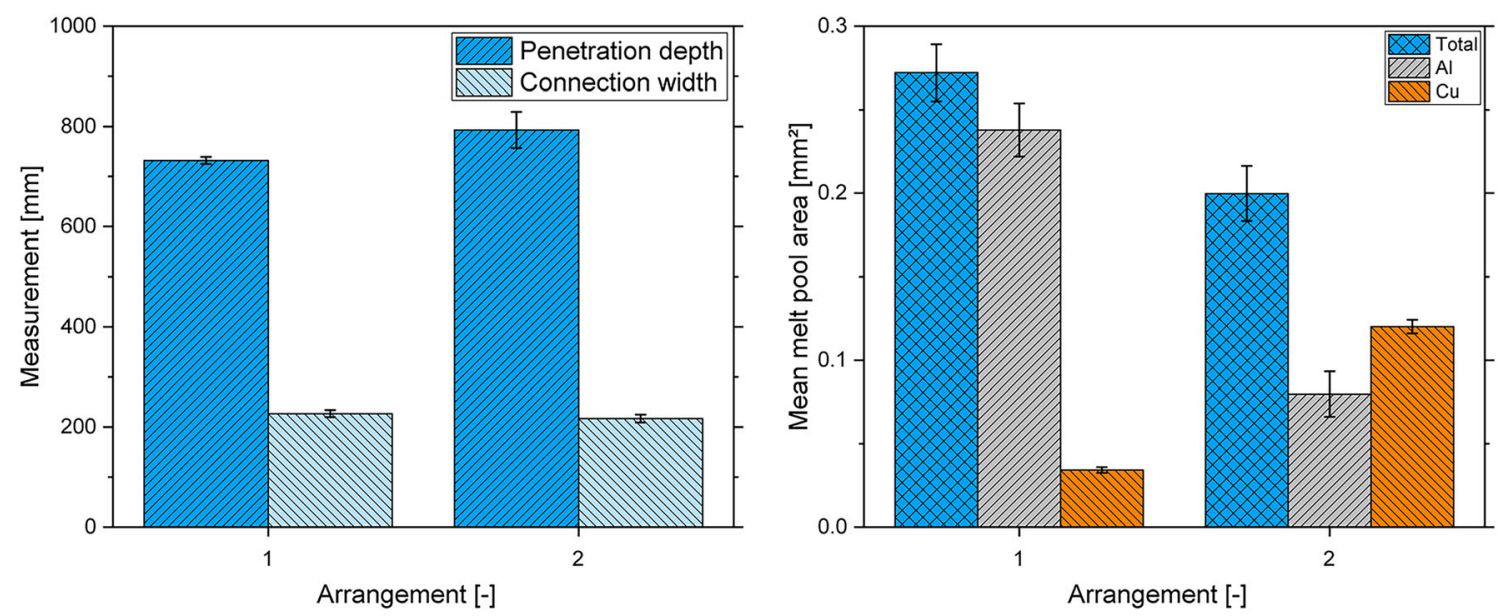

Fig. 9 Penetration depth and connection width (left) and mean melt pool area (right) for both arrangements 
Fig. 10 Scanning electron microscope pictures for both arrangements
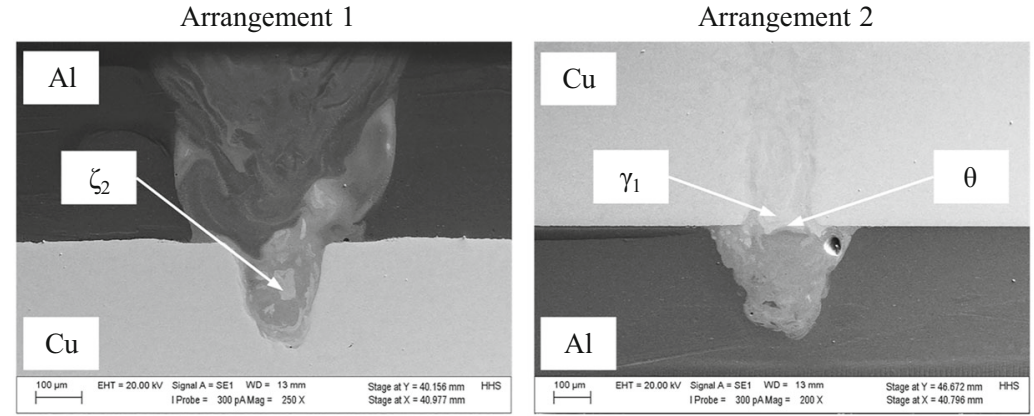

Analysing the longitudinal cross sections, pores, cracks and different colours of the molten material are visible, see Fig. 11. For welding of aluminium, pores can occur due to the solubility of hydrogen in liquid aluminium [18]. Due to a high solidification speed, the gas has no time to escape and forms pores in the melt pool. Furthermore, instabilities of the keyhole can lead to gaseous extractions that solidify in the molten pool.

With a higher ratio of aluminium in the melt pool, the pores have a larger size and solidify close to the transition area. The lower copper material in this case works as a heat sink and leads to fast cooling in this area of the weld seam. In arrangement 2, the pores occur often on the side of the weld seam under the transition area. The pores created in the bottom of the keyhole are displaced by the gas pressure of the keyhole. The resulting upstream around the keyhole moves the gas bubbles along the outside of the wide aluminium melt pool up to the transition area where they hit the solid copper material. Again, the copper works as a barrier and the pores solidify in this area.

Due to the high difference in the thermal expansion of the two materials, tensions arise in the solidified material. Cracks with a vertical or horizontal course are created as a result.

The colourful mixing in the longitudinal cross sections indicates the mixing of the materials. The different colours indicate the mixing ratio. In the magnifications on the right side in Fig. 11, the areas are marked. For arrangement 1 , the $\gamma_{1^{-}}$ phase lays on the weld seam bottom and shows some vertical turbulences. On top of it, a layer with $\theta$ and $\zeta_{2}$-phases is seen until the mixing is mainly pure aluminium. In comparison, arrangement 2 shows the opposite behaviour. A small layer of mainly pure aluminium is on the bottom of the weld seam, topped with a small layer with $\theta$ and $\zeta_{2}$-phases and a wide and turbulent area of $\gamma_{1}$-phase. Close to the surface, the copper is nearly pure. Aluminium as a bottom layer leads consequently to stronger vertical melt pool dynamics, which leads to an increased mixing along the weld depth.

\subsubsection{Mechanical properties}

The mechanical properties of the weld seams are investigated by performing tensile tests. The breaking force $\mathrm{F}_{\max }$ and the mean connection area are used to calculate the tensile shear strength to compare the different arrangements. The results are shown in Table 3 together with the results of welds with similar material configuration. For this, weld seams with copper to copper and aluminium to aluminium have been performed. While the pure aluminium joints show the lowest value, the copper joints offer the highest tensile shear strength. The dissimilar joints show values in between $164 \mathrm{~N} / \mathrm{mm}^{2}$ for arrangement 1 and $200 \mathrm{~N} / \mathrm{mm}^{2}$ for arrangement 2 .
Fig. 11 Longitudinal cross sections of both arrangements with magnifications of red square (mixing areas are outlined with red and blue in magnifications)
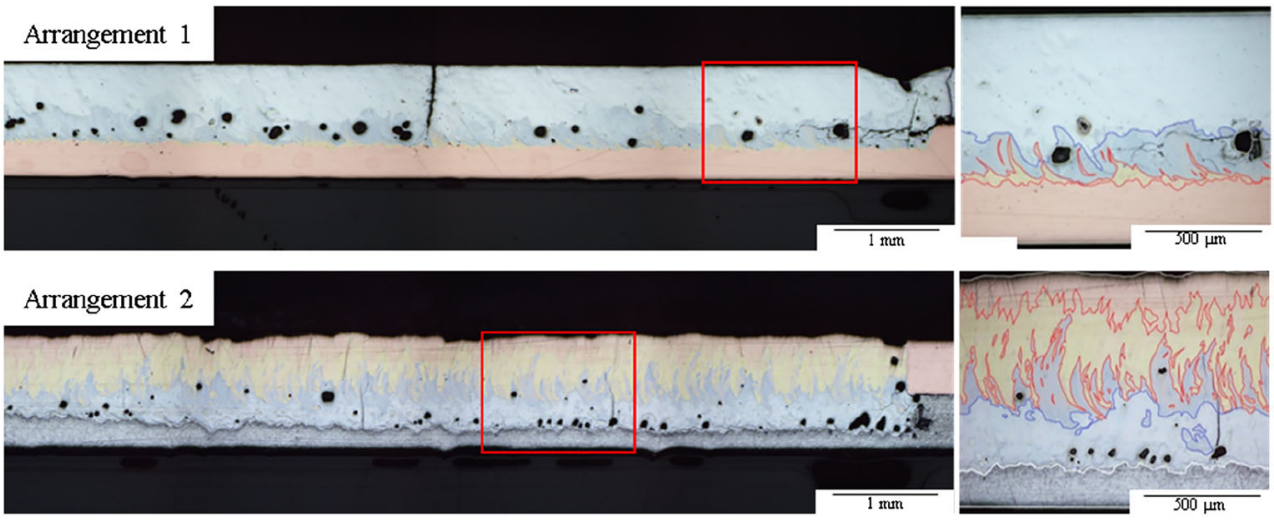
Table 3 Calculation of tensile shear strength

\begin{tabular}{lllll}
\hline & Al-Cu & Cu-Al & Al-Al & Cu-Cu \\
\hline Mean breaking force $\mathrm{F}_{\max }(N)$ & 373 & 433 & 470 & 812 \\
Standard deviations $(N)$ & 36 & 28 & 22.1 & 3.4 \\
Strain rate $\varepsilon(\%)$ & 1.10 & 0.76 & 1.36 & 1.62 \\
Mean connection width $(\mathrm{mm})$ & 0.227 & 0.217 & 0.465 & 0.310 \\
Standard deviations $(\mathrm{mm})$ & 7 & 8 & 8 & 2 \\
Weld seam length $(\mathrm{mm})$ & 10 & 10 & 10 & 10 \\
Connection area A $\left(\mathrm{mm}^{2}\right)$ & 2.27 & 2.17 & 4.65 & 3.1 \\
Tensile shear strength $\tau\left(\mathrm{N} / \mathrm{mm}^{2}\right)$ & 164 & 200 & 101 & 262 \\
\hline
\end{tabular}

The difference in the tensile shear strength is based on the different mixing ratio of the materials. The higher percentage of copper in the melt pool of arrangement 2 leads to a higher shear strength. This effect is supported by the occurrence of intermetallic phases, which show an increased hardness compared with the basic compounds. The $\gamma_{1}$-phase with its high hardness, see Table 1, is also a reason for the reduced strain rate stated in Table 3 . In comparison, the strain rate of arrangement 1 is higher which is caused by the position of the intermetallic phases. The phases are mainly positioned under the connection level, while the connection is mainly dominated by aluminium. In contrast, arrangement 2 shows upstreaming aluminium material and a phase formation all along the weld seam depth.

\section{Conclusion}

All in all, the influence of spatial power modulation on the weld seam geometry and intermetallic mixing of aluminium and copper during laser beam welding has been investigated. The typical weld seam geometry for two configurations can be changed using a circular oscillation. For aluminium on top of copper, the oscillation leads to a wider connection width. Using copper as a top layer, the used parameter range is smaller and the process as well as the cross-sectional shape is more sensitive to parameter changes.

The weld seam shape, characterized by depth and connection width, can be reproducibly reached with aluminium as a top layer. In the other configuration, the weld depth is subject to greater variations. Based on this, an investigation of the occurrence of intermetallic phases has been performed. The increased upstream of the lower aluminium layer leads to an increased mixing of the materials in this configuration, which is also seen in the reduced strain rate. Using aluminium as a top layer, most of the intermetallic phases occur in the bottom of the weld seam and not in the transition area.

For future investigations, different oscillation frequencies or different oscillation shapes are of interest. The differences in the path speed have an influence on the vertical melt pool dynamic which is responsible for the mixing of the two materials. With an elliptic shape, the melt pool can be elongated and influences the solidification of the material, which may have a positive effect on crack and pore formation. An additional evaluation should address the brittleness of the joint regarding long-term stability and cyclic loads induced by temperature or electricity.

Funding Information Open Access funding provided by Projekt DEAL.

Open Access This article is licensed under a Creative Commons Attribution 4.0 International License, which permits use, sharing, adaptation, distribution and reproduction in any medium or format, as long as you give appropriate credit to the original author(s) and the source, provide a link to the Creative Commons licence, and indicate if changes were made. The images or other third party material in this article are included in the article's Creative Commons licence, unless indicated otherwise in a credit line to the material. If material is not included in the article's Creative Commons licence and your intended use is not permitted by statutory regulation or exceeds the permitted use, you will need to obtain permission directly from the copyright holder. To view a copy of this licence, visit http://creativecommons.org/licenses/by/4.0/.

\section{References}

1. IEA (2019) Global EV Outlook 2019. Available: www.iea.org/ publications/reports/globalevoutlook2019/. Accessed 22.09.2019

2. Kothauer R (2013) Handbuch Lithium-Ionen-Batterien. Springer, Berlin

3. Brand M, Schmidt P, Zaeh M, Jossen A (2015) Welding techniques for battery cells and resulting electrical contact resistances. Journal of Energy Storage 1:7-14

4. Hügel H, Graf T (2009) Laser in der Fertigung. Vieweg + Teubner, Wiesbaden

5. Engler S, Ramsayer R, Poprawe R (2011) Process studies on laser welding of copper with brilliant green and infrared lasers. Physics Procedia 12

6. Poprawe R (2011) Tailored light 2. Springer, Berlin, Heidelberg

7. Haeusler A, Schuermann A, Schoeler C et al (2017) Quality improvement of copper welds by laser microwelding with the usage of spatial power modulation. Journal of Laser Applications 29 
8. Schmitt F (2012) Laserstrahl-Mikroschweißen mit Strahlquellen hoher Brillanz und örtlicher Leis-tungsmodulation. Dissertation, RWTH Aachen, Shaker, Aachen Germany

9. Haeusler A, Mehlmann B, Olowinsky A et al (2017) Efficient copper microwelding with fibre lasers using spatial power modulation. Lasers in Enginneering (Old City Publishing) 36:133-146

10. Kraetzsch $\mathrm{M}$ et al (2011) Laser beam welding with high-frequency beam oscillation: welding of dissimilar materials with brilliant fiber lasers. Phys Procedia 12:142-149

11. Mys I et al (2008) Verfahren zum Schweißen artungleicher metallischer Fügepartner, insbesondere von Aluminium-KupferVerbindungsstellen. Patent, DE102004009651B4

12. Petzold F et al (2013) Einfluss intermetallischer Phasen auf die Langzeitstabilität von ultraschallgeschweißten KupferAluminium-Kontakten. Metall 11

13. Choi $\mathrm{S}$ et al (2012) Vibration analysis in robotic ultrasonic welding for battery assembly. IEEE International Conference on Technologies for Practical Robot Applications (TePRA)
14. Schmidt A, Schweier M, Zaeh F (2012) Joining of lithium-ion batteries using laser beam welding: electrical losses of welded aluminum and copper joints. International Congress on Applications of Lasers \& Electro-Optics, LIA, pp 915-923

15. Deutsches Kupferinstitut (2005) Material Data Sheet: Cu-ETP. Online available: www.kupferinstitut.de. Accessed 18.09.2019

16. Schwarzwälder Metallhandel GmbH (2013) Material Data Sheet: EN AW 1050A [EN AW-A199.5], Online available: www.wielandsmh.de. Accessed 18.09.2019

17. Hess A (2012) Vorteile und Herausforderungen beim Laserstrahlschweißen mit Strahlquellen höchster Fokussierbarkeit. University of Stuttgart, Herbert Utz Verlag, Dissertation

18. Schinzel C (2002) Nd:YAG- Laserstrahlschweißen von Aluminiumwerkstoffen für Anwendungen im Automobilbau. University of Stuttgart, Herbert-Utz-Verlag

Publisher's note Springer Nature remains neutral with regard to jurisdictional claims in published maps and institutional affiliations. 